\title{
Urban heat island patterns and their dynamics based on an urban climate measurement network
}

\author{
TAMÁs GÁL, NóRA SKARBIT and JáNos UNGER ${ }^{1}$
}

\begin{abstract}
In this paper the spatial pattern of Urban Heat Island (UHI) and its dynamical background are analysed. Furthermore, we examined the annual, seasonal and diurnal characteristics of UHI according to the Local Climate Zones (LCZs). The analysis was performed using one year (between June 2014 and May 2015) dataset from the measurement network of Szeged (Hungary). This network consists of 24 stations measuring air temperature and relative humidity. In the installation of the network the representativeness played an important role in order to that the stations represents their LCZs. We examined the thermal reactions during average and ideal conditions using the so-called weather factor. Our results show that the UHI is stronger in the compactly built zones and there are great differences between the zones. The greatest values appear in summer, while the difference is small in winter. The UHI starts to develop at sunset and exists through approximately 9-10 hours and differences are about $2{ }^{\circ} \mathrm{C}$ larger in case of ideal days, when the conditions (wind, cloud cover) are appropriate to the strong development of the UHI. The cooling rates show that the first few hours after sunset are determinative for the developing of UHI. In addition, the effect of UHI on annual mean temperature is also significant.
\end{abstract}

Keywords: measurement network, Szeged, Urban Heat Island, Local Climate Zones, cooling rate

\section{Introduction}

High number of people lives in urban environments. These areas have a specific landscape and their complex surface results characteristic climate modifications. Within these modified climate the excess urban heat in the middle latitudes has primarily economic and health risk. This thermal modification nowadays has been recognized noticeably by the citizens, especially during heat waves, but, generally, it is connected with the climate change. It is not a question that the studies evaluating the global scale changes causing higher frequency of heat waves are important, but analyzing the climatic effect of the urban areas is as important.

The urban climate is defined as a local climate that is modified by the interactions between built-up area and regional climate (World
Meteorological Organization 1983). In this context, the elevated urban temperature (urban heat island, UHI) and its magnitude (UHI intensity) is defined as the temperature difference between rural and urban measurement sites.

The most reliable way to study the urban climate is the evaluation of urban scale measurements. There are several examples for this kind of measurements, but the problem is the findings of these studies are hard to adapt to different cities with different size, built-up characteristics and climatic background. To solve this discrepancy STEWART, I.D. and OKE, T.R. (2012) developed the Local Climate Zone (LCZ) system which is a climate-based classification of the surroundings of the urban and rural measuring sites which is applicable universally and relatively easily to local temperature studies using screen-level observations. Usage of this classification can help to

\footnotetext{
${ }^{1}$ Department of Climatology and Landscape Ecology, University of Szeged. H-6722 Szeged, Egyetem u. 2. E-mails: tgal@geo.u-szeged.hu, skarbitn@geo.u-szeged.hu, unger@geo.u-szeged.hu
} 
generalise the obtained results and it helps to adapt and compare the results to other but urban areas with similar features.

In this study, we present the results of an urban measurement network which was deployed using the concept of the Local Climate Zones, in order to reveal the differences in the thermal reactions of these different general zones. In addition, the novelty of this network representing the different LCZs is the high temporal and spatial resolution. Furthermore, the obtained data give the opportunity to analyse the temporal dynamics and spatial patterns of UHI.

Aims of this study are (i) to present briefly this measurement network, (ii) to evaluate some data of its first operational year in order to investigate the thermal reactions of different LCZs in annual, seasonal and daily timescale, and (iii) to analyze the spatial pattern and temporal dynamics of the UHI and nocturnal cooling rate. Also an important question is (iv) the magnitude of the urban effects for the mean annual temperature of the study area.

\section{Study area and measurement network}

Szeged is a medium sized city with a population of approximately 170,000. It is located at a nearly flat terrain in the south-eastern part of Hungary as part of the Great Hungarian Plain. Szeged is divided into two parts by the Tisza River. As far as the climate of Szeged is concerned it is in the Cfb climate type according to Köppen climate classification system (Коттек, M. et al. 2006). The city centre is densely built-up, the northern part consist of mostly 5-10 storey residential buildings and family houses are located at the outskirts (UNGER, J. et al. 2001).

An automatic GIS-method was used to determine the existing LCZs and their extensions in the study area (LeLovics, E. et al. 2014). According to this method seven built-up LCZs can be found in and around Szeged and our study area covers six of them (Figure 1). The compact zones (LCZs 2 and 3) are found in the downtown, while the open and large lowrise and sparsely built zones are mainly in the outskirts. However, the open midrise zone appears in the centre and in the north-northeast parts of the city too.

A monitoring network was established in Szeged within the framework of an EU project (URBAN-PATH 2016). 24 stations were installed measuring air temperature and relative humidity. The locations of the stations are selected to fulfil two criteria: (I) stations have to be representative for the LCZs within the city, (II) spatial pattern of the network have to be capable to reveal the spatial structure of the UHI. The location process is presented by Lelovics, E. et al. (2014) and UNGER, J. et al. (2015).

The purpose of this network was the examination of excess heat and its intra-urban patterns in the city with appropriate spatial and temporal resolution. The spatial resolution ensures the accurate differences between the particular neighbourhoods, while the temporal resolution provides appropriate dataset for diurnal analysis. From the processed data graphs and high-resolution maps where drawn and presented on the Internet and a public screen thus useful information is provided for the general public (UNGER, J. et al. 2015).

The data are provided by a Sensirion SHT25 sensor in a radiation protection screen $(220 \times 310$ $\mathrm{mm}$ ) at the end of a $60 \mathrm{~cm}$ console (Photos 1-3). The shield is the same as the model used by the Hungarian Meteorological Service (HMS). The accuracy of the sensor is $0.4{ }^{\circ} \mathrm{C}$ and $3 \%$ for the temperature and humidity, respectively.

The consoles are mounted on lamp posts at a height of $4 \mathrm{~m}$ above the ground for security reasons. As the air in the urban canyon is well-mixed, the temperature measured at this height is representative for the lower air layers too (Nakamura, Y. and OкE, T.R. 1988). The stations send the readings to a server in every 10 minute, so this database can be a basis of further analysis with 10 minute time resolution. For further technical details about the sensors, logging, transmission, and online displaying of the data see UNGER, J. et al. (2015). 


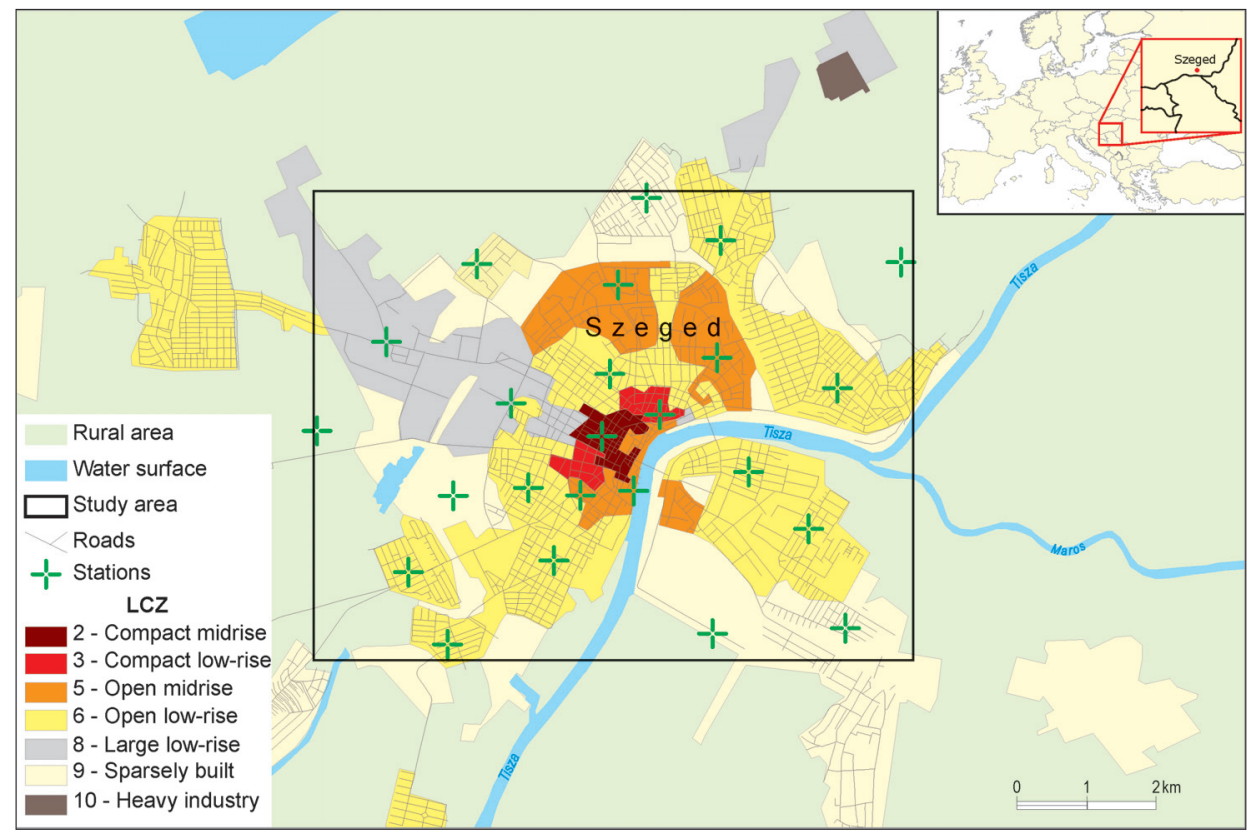

Fig. 1. LCZ map and station locations of the urban monitoring network in Szeged

The extent of the study area is determined by the locations of stations and it covers an 8.6 $\mathrm{km} \times 6.7 \mathrm{~km}$ rectangle (see Figure 1). For this study we used a one-year period (from June 1, 2014 to May 31, 2015) temperature dataset of the monitoring network.

For the analysis spatial and temporal mean values were calculated in order to represent the different aspects of UHI. In case of spatial mean values the stations data within a given LCZ type were averaged. By temporal aspect first we calculated the sunset in each day. Time of sunset assigned as the beginning of a relative timescale, and using it we calculated the hourly mean temperature for each station. In this timescale 0 hour is the time of sunset, negative and positive hours are before and after the sunset, respectively. Using this approach the long term (seasonal, yearly) mean temperature or UHI intensity development as a result of cooling process can be calculated and compared as the effect of the different time of sunset is filtered out.

For evaluation of UHI and nocturnal cooling a selection of days with ideal conditions is helpful. Ideal weather conditions help to reveal the urban effect on the thermal environment. The selection of the ideal days is based on the weather factor, $\Phi_{w}$ (OKE, T.R. 1998) which is calculated as:

$$
\Phi_{w}=u^{-\frac{1}{2}}\left(1-k n^{2}\right),
$$

where $u$ is the wind speed $(\mathrm{m} / \mathrm{s}), k$ is the Bolz correction factor for cloud height (BoLz, H.M. 1949), $n$ is the cloud amount in tenths. In our case, the $\Phi_{w}$ values calculated for one-hour intervals using the data from the HMS (Hungarian Meteorological Service) station in Szeged. The obtained values were averaged from sunrise to the next sunrise (about 24 hours) as the weather conditions in daylight hours prior to the night and during the night affect mostly the nocturnal air temperature differences above the varied surfaces.

In order to isolate the very specific weather conditions that promote microclimate formation the days with average $\Phi_{w}>0.7$ were regarded as ideal days, similar to STEWART, I.D. et al. (2014). 


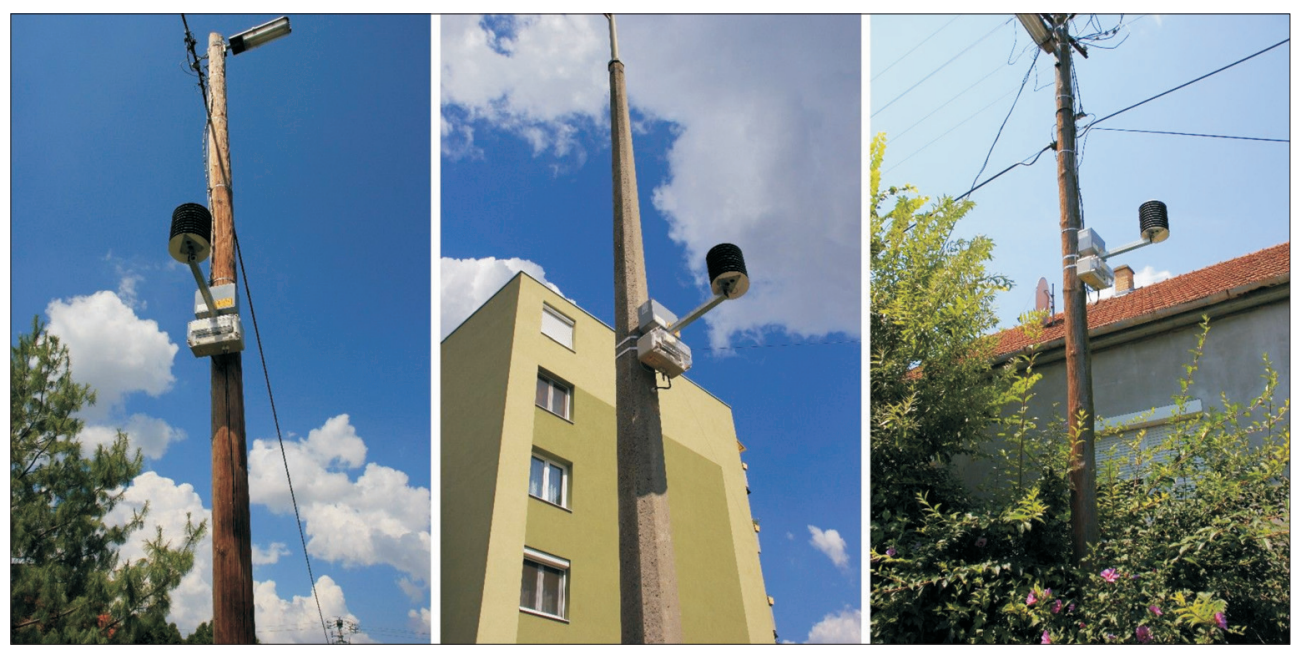

Photos 1-3. Typical setup of monitoring stations

\section{Results}

Annual, seasonal and diurnal characteristics of UHI

Figure 2 presents the annual and seasonal mean maximum nocturnal temperature differences from station HMS in each LCZ zone. It can be generally established that the highest values appear in summer except in LCZ 9 and are followed by the values of spring. The second lowest temperature differences are in autumn and the smallest values can be found in the winter season. The average

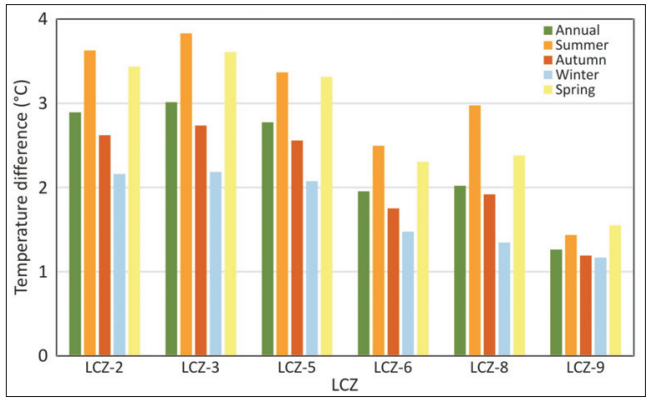

Fig. 2. Annual and seasonal mean maximum nocturnal temperature differences from HMS station by LCZ types (Szeged, June 2014 - May 2015) annual differences are between the means of spring and autumn.

If we see the differences among the LCZs the sequence is the same in each season and also annually except from a small deviation. The highest values are in the compact zones and among them the LCZ 3 has the larger differences. In this compact midrise zone, the maximum value is $3.8^{\circ} \mathrm{C}$, while the minimum is $2.2^{\circ} \mathrm{C}$. In LCZ 2 the minimum value is the same, but the maximum is lower by $0.2{ }^{\circ} \mathrm{C}$. They are followed by LCZ 5, where the values range from $2.1^{\circ} \mathrm{C}$ to $3.4^{\circ} \mathrm{C}$. In case of winter, LCZ 6 is the next warmest zone, which is followed by LCZ 8. In the other seasons and annual basis, LCZ 6 follows LCZ 8. The maximum value in LCZ 8 is $3.0{ }^{\circ} \mathrm{C}$ and the minimum is $1.3^{\circ} \mathrm{C}$, while for LCZ 6 there are $2.5^{\circ} \mathrm{C}$ and $1.5^{\circ} \mathrm{C}$, respectively. The minimal temperature differences are in LCZ 9 in every case and they range from $1.2{ }^{\circ} \mathrm{C}$ to $1.6^{\circ} \mathrm{C}$.

Investigating the extent of the difference among the zones the biggest deviation, namely, the difference occurs between LCZs 3 and 9: it is approximately $2.4{ }^{\circ} \mathrm{C}$ is in summer and $2.1^{\circ} \mathrm{C}$ for spring. They are followed by the annual value of $1.8^{\circ} \mathrm{C}$ and the smallest differences are in autumn $\left(1.5^{\circ} \mathrm{C}\right)$ and in winter $\left(1.0^{\circ} \mathrm{C}\right)$. 
On ideal days, the annual and seasonal mean maximum nocturnal temperature differences from the HMS station in each LCZ zone are presented in Figure 3. In this case, the summer values are not the highest in each case. In LCZs 3, 5 and 9 the values of autumn are higher and in LCZ 8 the spring value exceeds both of them. The winter season shows the minimal values except for LCZ 9, where the average spring temperature difference is only $0.1^{\circ} \mathrm{C}$. The annual values follow the summer and autumn differences aside from LCZ 8 , where the spring season exceeds it too.

Aside from summer and spring, the maximum differences appear in LCZ 3. In this zone the values range from $3.3^{\circ} \mathrm{C}$ to $4.7^{\circ} \mathrm{C}$. In summer and spring, LCZ 2 has larger values, where the maximum is $4.8^{\circ} \mathrm{C}$ and the minimum is $3.3^{\circ} \mathrm{C}$. In autumn the second warmest zone is LCZ 5 instead of LCZ 2, while in the other periods it is on the third place. In this zone, the values range from $3.2{ }^{\circ} \mathrm{C}$ to $4.7^{\circ} \mathrm{C}$. The sequence of the other zones is the same in every season and annually. The next is the large low-rise zone with values between $2.0^{\circ} \mathrm{C}$ and $3.4{ }^{\circ} \mathrm{C}$. It is followed by LCZ 6, where the maximum is $2.9^{\circ} \mathrm{C}$ and the minimum is $1.9^{\circ} \mathrm{C}$. As expected, the minimal temperature differences are in LCZ 9 where the values range from $0.1^{\circ} \mathrm{C}$ to $1.4^{\circ} \mathrm{C}$. Because of the low values in LCZ 9 the differences between the zones is the highest in spring when the deviation approaches $4.2{ }^{\circ} \mathrm{C}$. The second biggest deviation appears

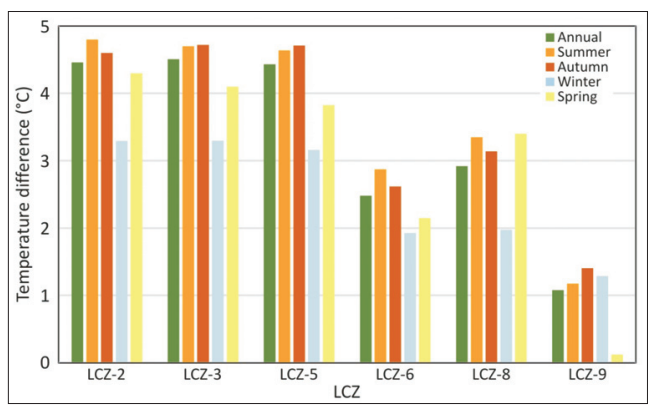

Fig. 3. Annual and seasonal mean maximum nocturnal temperature differences from HMS station by LCZ types on ideal days (Szeged, June 2014 - May 2015) in summer with a value of $3.6{ }^{\circ} \mathrm{C}$. It is followed by the annual $\left(3.4{ }^{\circ} \mathrm{C}\right)$ and autumn $\left(3.3^{\circ} \mathrm{C}\right)$ differences, which are almost the same. The smallest difference is in winter (approximately $2^{\circ} \mathrm{C}$ ).

In Figure 4, the combined annual and diurnal variations of average temperature difference of LCZs from station HMS are presented. The separation of the nocturnal and daily hours and the seasonal changes are obvious and clearly seen except LCZ 9, where the differences are small and there is no unequivocal tendency. This separation is the most noticeable in case of the compact zones and open midrise zone and becomes less characteristic in LCZ 6 and 8.

In the compact zones a much more characteristic temperature difference develops in summer than in the other zones. The difference is around $4-6{ }^{\circ} \mathrm{C}$ and it exists through several days. In case of LCZ 9, there is no clear tendency of temperature, so this builtup type affects the temperature in the least.

Other important phenomenon the urban cool island also appears in Figure 4. At daytime in all seasons except winter the urban built-up types have lower temperatures than the rural ones as the daytime warming is slower because of the shading effect of buildings. This cool island effect clearly observable in types with dense built-up characteristics (LCZs 2, 3, 5) and less obvious in the case of large low-rise and almost completely disappears in case of LCZs 6 and 9.

\section{Spatial pattern and night-time dynamics of UHI}

The nocturnal changes of the spatial patterns of UHI are also important to analyze. We examined the nocturnal dynamics of the average UHI intensity from 1 hour before sunset to 13 hours after sunset regarding the HMS station as rural one (Figure 5). These maps represent the yearly mean values in the given times, so these maps contain every weather situation including the unfavourable ones too when the urban thermal modification effect is weak. 


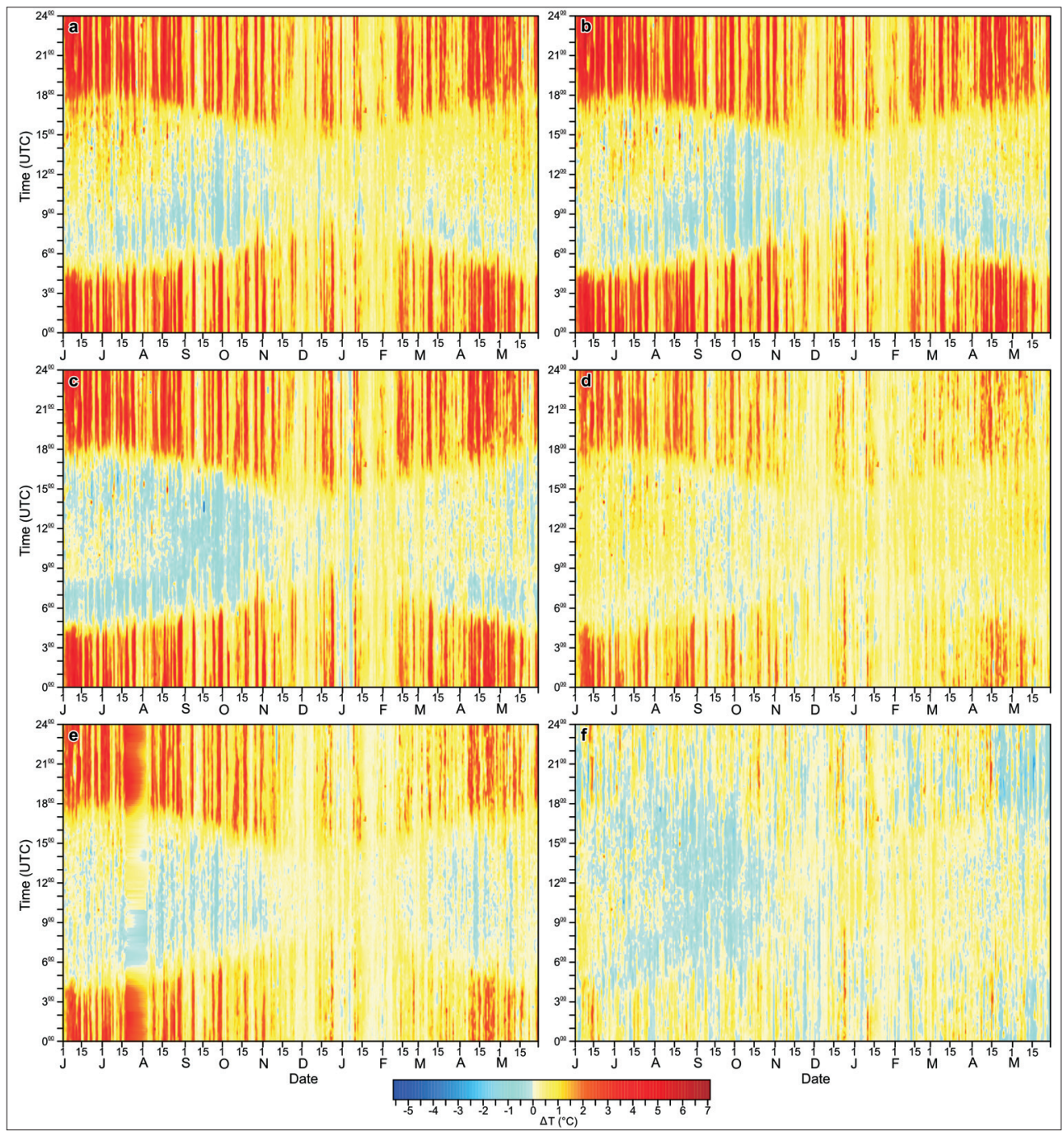

Fig. 4. Annual and diurnal variations of average temperature difference $(\Delta \mathrm{T})$ of LCZs from HMS station. $\mathrm{a}=\mathrm{LCZ} 2$ - HMS, b = LCZ 3 - HMS, c = LCZ 5 - HMS, d = LCZ 6 - HMS, e = LCZ 8 - HMS, f = LCZ 9 - HMS)

(Szeged, June 2014 - May 2015)

Before sunset there is no characteristic pattern, the UHI starts to develop at sunset and it reaches rapidly its maximum development in the next two hours (Figure 5). Under these average conditions, only a relatively weak UHI develops as its maximum intensity is around $2{ }^{\circ} \mathrm{C}$ and it is mostly observable in city centre. At the first few hours (until +3 hours) negative values can be found in a small area in the western part of the city. The reason for this is the microclimatic background of these areas (small lakes).

The UHI remains relatively strong during the rest of the nocturnal hours and it starts to decrease rapidly at 10-11 hours after sunset. The shape of the $1{ }^{\circ} \mathrm{C}$ isotherm is almost the same from 1 hour until 8 hour after sunset. The pattern of the area with minimum $1{ }^{\circ} \mathrm{C}$ 

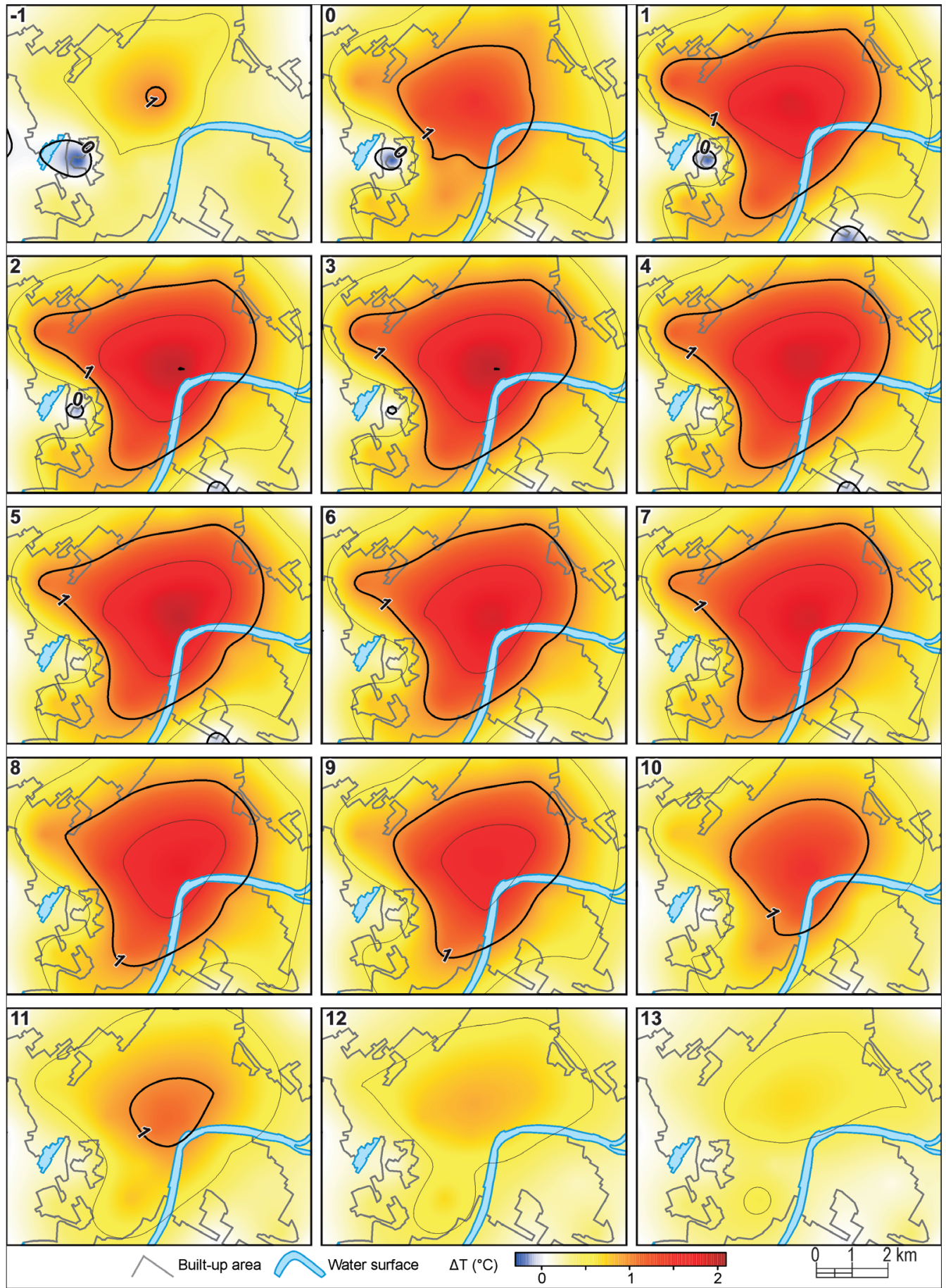

Fig. 5. Patterns of building up and down of average annual UHI intensity ( $\Delta \mathrm{T})$ (from sunset $-1 \mathrm{~h}$ to sunset $+13 \mathrm{~h}$ ) (Szeged, June 2014 - May 2015) 

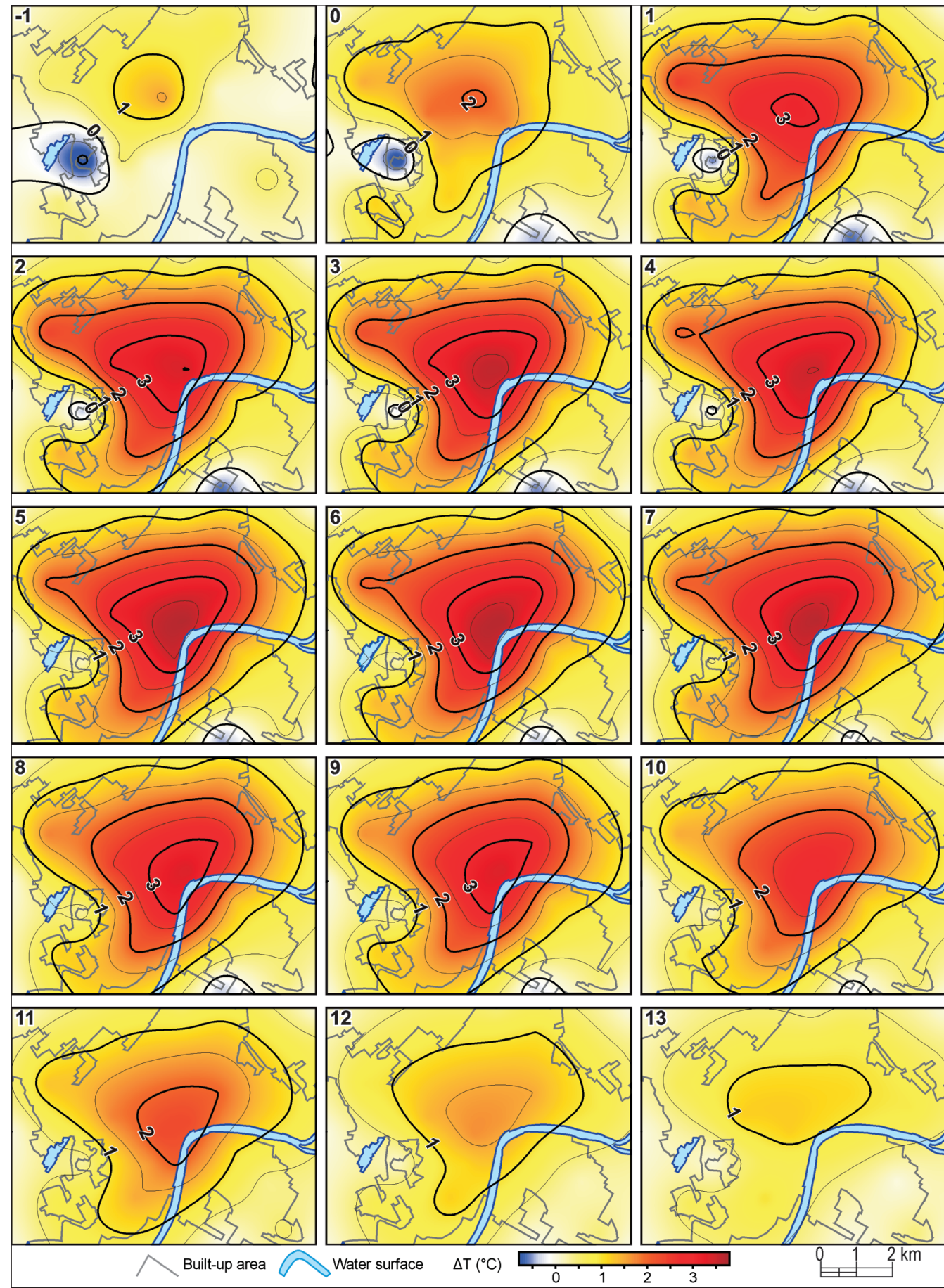

Fig. 6. Patterns of building up and down of average annual UHI $(\Delta \mathrm{T})$ on the selected ideal days (from sunset-1h to sunset+13h) in Szeged (June 2014 - May 2015) 
difference stretch northwest and southwest directions and dominates the largest part of the city. It reflects the spatial pattern of the different LCZ types (see Figure 1), namely the most dense local climate zones has larger temperature surplus.

In the inner parts of the city (basically the city core) the magnitude of UHI reaches at least $1.5^{\circ} \mathrm{C}$. It appears at 1 hour after sunset and last +9 hours. Its extension is slightly changed during the night and it starts to decrease about 8 hours after sunset. Around 10 hours after sunset the UHI starts to collapse and around +12 or 13 hours it completely disappears.

If we concentrate on the favourable weather conditions, then we can found much stronger UHI intensity (Figure 6). In this case, the temporal dynamics of the UHI pattern is differs from the case of annual mean values. The maximum intensity is around $4{ }^{\circ} \mathrm{C}$ which is almost twice as large as the maximum in Figure 5.

The UHI starts to develop at sunset but the temperature difference of $2{ }^{\circ} \mathrm{C}$ already appears at this hour. In the next hour the extension of differences over $2{ }^{\circ} \mathrm{C}$ increases and values over $3{ }^{\circ} \mathrm{C}$ also appear. Later, the UHI becomes more and more extensive and its intensity increases also. The differences over $3{ }^{\circ} \mathrm{C}$ dominate the city centre and the remaining parts have values between $1^{\circ} \mathrm{C}$ and $2{ }^{\circ} \mathrm{C} .3$ hours after sunset the intensity exceeds $3.5^{\circ} \mathrm{C}$ in the centre and after a small weakening it continuously increases again. The weakening of the UHI starts at 7 hours after sunset when the area with values over $3.5^{\circ} \mathrm{C}$ difference decreases and it disappears at +8 hours. For this time, the areas which are delimited by the other isotherms decrease and later gradually disappear. At about +10 hours, there are still some temperature differences, but it decreases continuously and around 12 and 13 hours it is minimal.

The spatial patterns of the UHI from the first hour until the $7^{\text {th }}$ hour are almost identical, thus the temperature surplus develops in the first hours of the night and it is present in the same areas with almost constant values during the night.

\section{Dynamical background of nocturnal UHI at favourable weather conditions}

It helps to understand the background of the development of the nocturnal temperature excess if we evaluate the spatial patterns of average hourly cooling rates (Figure 7). In order to avoid the drastic temperature changes caused by synoptic scale weather changes, we analyse only the mean hourly cooling/warming rates calculated from the data of ideal days.

The most intensive cooling is at sunset and 1 hour after sunset. At this time, the cooling rate in the city centre is over $-1.5^{\circ} \mathrm{C}$ and in the largest parts of the city it is over $-2^{\circ} \mathrm{C}$. In the rural areas the cooling rate is under $-2.5^{\circ} \mathrm{C}$, showing that the rural areas cool faster. These different rates cause the development of UHI and it can be clearly seen that the hours around sunset are crucial for this phenomenon. In the following hours, the cooling rate decreases and there is no significant spatial trend until sunrise. At 10 hours after sunset, the warming process appears and the rate continuously increases. One hour later the warming rate is under 0.5 ${ }^{\circ} \mathrm{C}$ in the city but it is larger in the outskirts and rural areas. In the following periods, the warming reaches $1{ }^{\circ} \mathrm{C}$ and $1.5^{\circ} \mathrm{C}$ in the city and in the outskirts, respectively. These differences in the warming rates are the reason of the development of the daytime urban cool island presented above.

\section{Effect of the UHI on annual temperatures}

In the previous sections we analysed the different aspects of the urban temperature modification: large positive values at night and smaller negative values in the daytime. The crucial question arises whether the nocturnal temperature surplus modifies the spatial pattern of basic climate indices like mean annual temperature. In order to answer this question, we depicted the spatial pattern of this measure (Figure 8).

As we can see on Figure 8, the effect of UHI is significant. Due to the higher nocturnal temperatures the annual mean temperature 

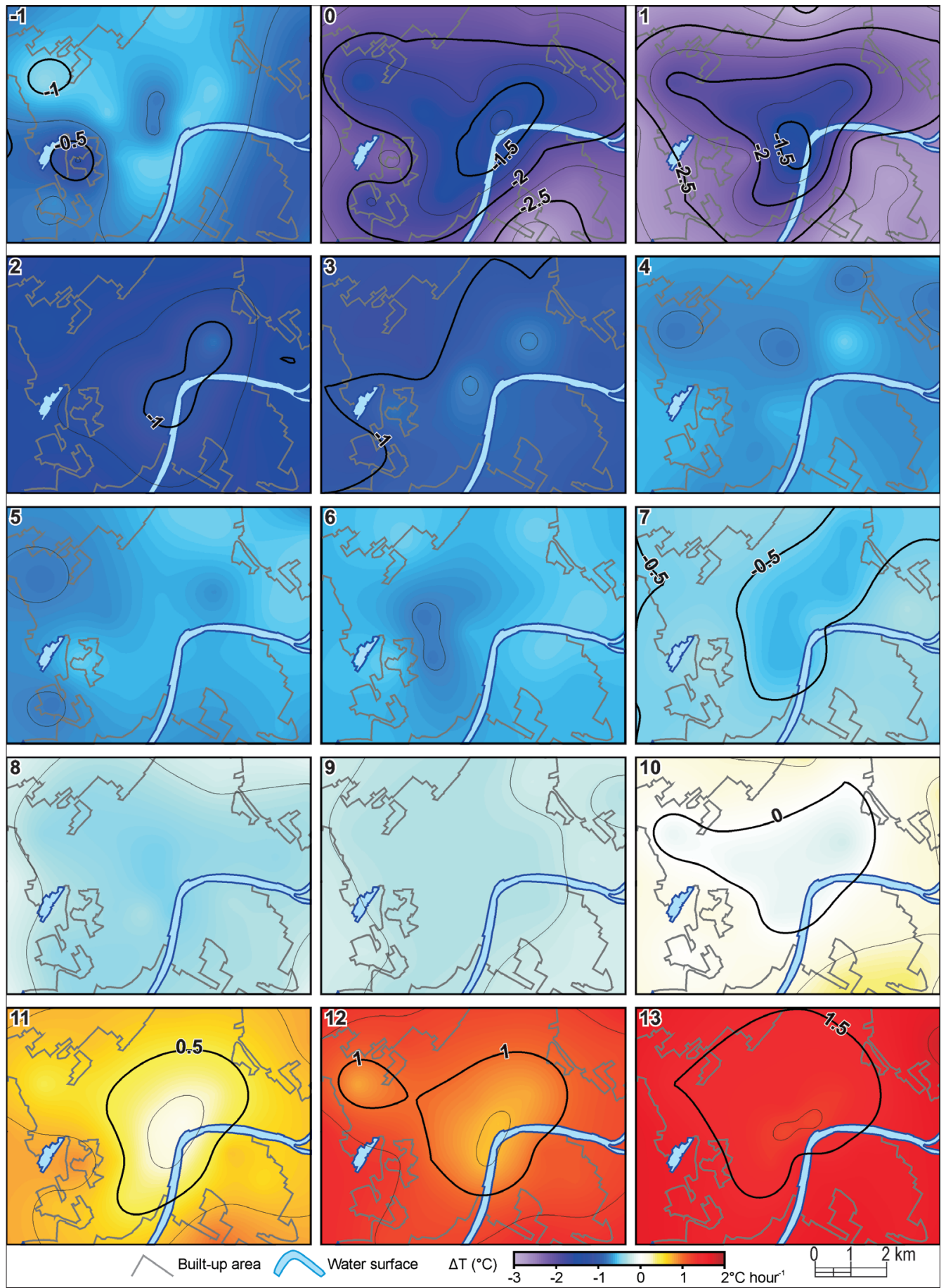

Fig. 7. The average patterns of hourly cooling/warming rates on ideal days (from sunset-1h to sunset+13h) (Szeged, June 2014 - May 2015) 


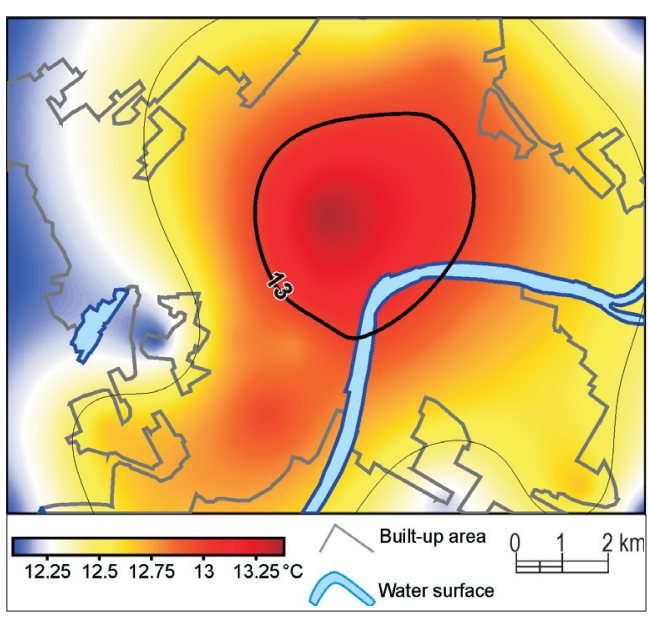

Fig. 8. Annual mean temperature pattern in Szeged (June 2014 - May 2015)

in the inner part of the city is $1^{\circ} \mathrm{C}$ higher than the rural one. We have to consider that in this mean value the unfavourable weather conditions and the lower daytime temperatures are also take part.

\section{Conclusions}

In this paper, we examined the features of the UHI in Szeged including its annual, seasonal and diurnal characteristics, furthermore its build up and down with the dynamical background. We analysed also the differences between the LCZs in terms of UHI. In the course of this analysis, we investigated the UHI intensity both in average and at ideal conditions. This examination was carried out using 1 year dataset from a 24-station urban measurement network.

From our results, we highlight the following statements. Between the LCZs the greatest urban/rural temperature differences appear in the compact zones. These zones are followed by open midrise and the other lowrise zones, while the smallest differences are in the sparsely built zone. Among the seasons outstanding values are in summer for every LCZ. Considering the ideal conditions, the autumn values are higher in some cases. The strong summer UHI is the most spectacular in LCZs 2, 3 and 5. Furthermore, these zones are cooler than the others relative to the rural area at daytime.

It can be generally noted that the mean annual UHI starts to develop immediately after sunset and exists approximately until 9 hours after sunset. It reaches its maximal intensity about 3 hours after sunset. At ideal conditions a much stronger UHI develops as its intensity approximately $2{ }^{\circ} \mathrm{C}$ greater than in average conditions. After sunrise the UHI starts to build down, but on ideal days there is small temperature difference even at this time. Considering the cooling rates the greatest changes appear around sunset and sunrise. The largest cooling is at sunset and 1 hour after sunset: in the rural areas the cooling is more intensive resulting in the urban heat excess. After sunrise the city warms slower than the rural areas, therefore, the urban cool island also occurs.

Finally, we evaluated the annual mean temperature, and we find that the urban temperature modification effect clearly appears in it. That is, the basically nocturnal thermal differences which are significant in case of ideal weather conditions can affect the general climate characteristics of the area. Therefore, any climate assessment or climate modelling work has to take into consideration the urban effect otherwise the results will underestimate the heat load of the urban areas.

Acknowledgements: The study was supported by the Hungarian Scientific Research Fund (OTKA K111768) and the first author was supported by the János Bolyai Research Scholarship of the Hungarian Academy of Sciences.

\section{REFERENCES}

Bolz, H.M. 1949. Die Abhängigkeit der infraroten Gegenstrahlung von der Bewölkung. Zeitschrift für Meteorologie 3. 201-203.

KotteK, M., Grieser, J., Beck, C., Rudolf, B. and Rubel, F. 2006. World Map of the Köppen-Geiger climate classification updated. Meteorologische Zeitschrift 15. (3): 259-263.

Lelovics, E., Unger, J., Gál, T. and Gál, C.V. 2014. Design of an urban monitoring network based on 
Local Climate Zone mapping and temperature pattern modelling. Climate Research 60. 51-62.

NaKamura, Y. and OKe, T.R. 1988. Wind, temperature and stability conditions in an east-west oriented urban canyon. Atmospheric Environment 22. 2691-2700.

Оке, T.R. 1998. An algorithmic scheme to estimate hourly heat island magnitude. In Preprints, $2^{\text {nd }}$ Urban Environment Symposium, 2-6.

Stewart, I.D. and OкE, T.R. 2012. Local Climate Zones for urban temperature studies. Bulletin of the American Meteorological Society 93. 1879-1900.

Stewart, I.D., Oke, T.R. and Krayenhoff, E.S. 2014. Evaluation of the 'local climate zone' scheme using temperature observations and model simulations. International Journal of Climatology 34. 1062-1080.
Unger, J., Gál, T., Csépe, Z., Lelovics, E. and Gulyás, Á. 2015. Development, data processing and preliminary results of an urban human comfort monitoring and information system. Időjárás (Quaterly Journal of Hungarian Meteorological Service) 119. 337-354.

Unger, J., SÜmeghy, Z., GulYÁs, Á., Bottyán, Z. and Mucsi, L. 2001. Land-use and meteorological aspects of the urban heat island. Meteorological Applications 8. 189-194.

URBAN-PATH homepage 2016. http://urban-path.hu/ (last accessed 2016-01-27)

World Meteorological Organization 1983. Abridged final report, $8^{\text {th }}$ session. Geneva, Commission for Climatology and Applications of Meteorology (WMO No. 600). 